\section{Alfentanil and fentanyl sedation in infants and small children during cardiac catheterization}

\begin{abstract}
Thirty patients aged $1-23 \mathrm{mth}$ received either alfentanil or fentanyl for the induction and maintenance of IV sedation during cardiac catheterization following oral flunitrazepain premedication $\left(0.1 \mathrm{mg} \cdot \mathrm{kg}^{-1}\right)$. Patients breathed spontaneously $30 \mathrm{per}$ cent oxygen in air. Both alfentanil and fentanyl abolished all reaction to pain and discomfort with minimal haemodynamic and respiratory changes. Induction doses of alfentanil and fentanyl were $20 \pm 6$ and $2.5 \pm 1.1$ (mean $\pm S D) \mu g \cdot \mathrm{kg}^{-1}$, respectively, and maintenance requirements $30 \pm 12$ and $l .5 \pm$ $0.6 \mu \mathrm{g} \cdot \mathrm{kg}^{-1} \cdot \mathrm{h}^{-1}$, respectively. These requirements were comparable among younger and older as well as cyanotic and acyanotic patients. The $I V$ sedation described adds an effective method to the armamentarium of an anaesthetist working in the cardiac laboratory.
\end{abstract}

Trente patients âgés de là 23 mois ont reçu soit de l'alfentanil soit du fentanyl pour l'induction et le maintien de la sédation intraveineuse durant le cathétérisme cardiaque après une prémédication au flunitrazépam $\left(0,1 \mathrm{mg} \cdot \mathrm{kg}^{-1}\right)$. Les patients respiraient spontanément 30 pour cent d'oxygène dans l'air. $L$ alfentanil el le fentanyl ont aboli la réaction et la douleur avec des changements minimes tant hémodynamiques que respiratoires. Les doses d'induction d'alfentanil et de fentanyl étaient respectivement $20 \pm 6$ et $2,5 \pm 1, I$ (moyenne $\pm S D) \mu \mathrm{g} \cdot \mathrm{kg}^{-I}$, respectivement, et les doses de maintien étaient $30 \pm 12$ et 1,5 $\pm 0.6 \mu \mathrm{g} \cdot \mathrm{kg}^{-1} \cdot \mathrm{hres}^{-1}$, respectivement. Ces doses étaient comparables chez les jeunes et les moins jeunes ainsi que chez les patients présentant une cyanose ou ceux qui étaient acyano.

\section{Key words}

ANAESTHESIA: paediatric;

ANAESTHETIC TECHNIQUES: intravenous sedation; ANAESTHETICS, INTRAVENOUS: alfentanil, fentanyl; HEART: catheterization.

From the Department of Anaesthesia, Children's Hospital, University of Helsinki, SF-00290 Helsinki, Finland.

Address correspondence to: Dr. Olli Meretoja, Children's Hospital, SF-00290 Helsinki, Finland.

The financial support given by the Paulo Foundation, Helsinki, is kindly recognized. tiques. La sédation intraveineuse décrite ajoute une méthode efficace à l'armatorium de l'anesthésiste auvrant dans le laboratoire de cardiologie.

Paediatric patients are usually either anaesthetized or sedated for cardiac catheterization in order to achieve reliable pressure and shunt values. ${ }^{1-3}$ Ideal conditions for these investigations would be produced during an anaesthetic or sedative technique which abolishes reactions to noxious stimuli, maintains normal blood gases, and produces minimal haemodynamic changes. However, little has been documented about the different anaesthesia practices for cardiac catheterizations. ${ }^{4}$ For years, our practice has been to sedate all children for these procedures by using low-dose ketamine, fentanyl or their combination following a flunitrazepam premedication. For the present study, we wanted to evaluate if alfentanil can be used like fentanyl for the sedation of infants and small children during cardiac catheterization. Furthermore, the dose-requirement of these agents was titrated to estimate their dose-effect characteristics and potency ratios.

\section{Methods}

Thirty ASA physical status III patients of less than two years of age admitted for elective cardiac catheterization were studied following the Institutional Ethical Committee approval and after informed consent received from the parents. Patients were randomly allocated to receive either alfentanil or fentanyl during their catheterization procedure. The patient data are shown in Table I: 12 patients were cyanotic, 18 were digitalized and 11 received diuretic (furosemide) therapy.

Patients received EMLA ${ }^{\circledR}$ cream on the groin and hands two hours before arriving at the cardiac laboratory. Thirty minutes after premedication (oral flunitrazepam solution $\left.0.1 \mathrm{mg} \cdot \mathrm{kg}^{-1}\right)$ an IV cannula was inserted and an infusion $\left(60 \mathrm{mmol} \cdot \mathrm{L}^{-1} \mathrm{NaCl}\right.$ in five per cent dextrose) was commenced at a rate of $4 \mathrm{ml} \cdot \mathrm{kg}^{-1} \cdot \mathrm{hr}^{-1}$. Glycopyrrolate $5 \mu \mathrm{g} \cdot \mathrm{kg}^{-1}$ was given IV. The patients were then given incremental doses of either alfentanil $3-5 \mu \mathrm{g} \cdot \mathrm{kg}^{-1}$ 
TABLE I Patient characteristics

\begin{tabular}{|c|c|c|c|c|c|c|c|c|c|c|c|}
\hline \multicolumn{6}{|c|}{ Alfentanil group } & \multicolumn{6}{|c|}{ Fentanyl group } \\
\hline$\#$ & $\begin{array}{l}\text { Age } \\
y r\end{array}$ & $\begin{array}{l}\text { Weight } \\
\mathrm{kg}\end{array}$ & Diagnosis & Cyanosis & Medication & $\#$ & $\begin{array}{l}\text { Age } \\
y r\end{array}$ & $\begin{array}{l}\text { Weight } \\
k g\end{array}$ & Diagnosis & Cyanosis & Medication \\
\hline 1 & 0.2 & 4.6 & AVSD+PDA & no & $\mathrm{DF}$ & 1 & 0.1 & 4.0 & $\mathrm{COA}$ & no & $\mathrm{F}$ \\
\hline 2 & 0.2 & 5.0 & TGA & yes & - & 2 & 0.1 & 3.2 & VSD +PH & no & DF \\
\hline 3 & 0.3 & 6.0 & $A S D+V S D$ & no & $\mathrm{DF}$ & 3 & 0.1 & 4.1 & $\mathrm{CoA}$ & no & DF \\
\hline 4 & 0.3 & 6.5 & PS + ASD & no & - & 4 & 0.2 & 5.1 & $\mathrm{CM}$ & no & - \\
\hline 5 & 0.4 & 6.1 & $\mathrm{VSD}+\mathrm{PH}$ & no & $\mathrm{D}$ & 5 & 0.2 & 3.0 & TGA + VSD & yes & $\mathrm{DF}$ \\
\hline 6 & 0.6 & 4.6 & $\mathrm{VSD}+\mathrm{PH}$ & no & $\mathrm{DF}$ & 6 & 0.3 & 3.0 & $V S D+C O A$ & no & $\mathrm{DF}$ \\
\hline 7 & 0.6 & 5.0 & PA & yes & - & 7 & 0.3 & 5.7 & TGA & yes & $\mathrm{D}$ \\
\hline 8 & 0.7 & 9.2 & TOF & yes & - & 8 & 0.3 & 3.4 & TGA+VSD & yes & - \\
\hline 9 & 0.9 & 8.9 & TOF & no & - & 9 & 0.5 & 5.8 & DORV + PS & yes & $\mathrm{D}$ \\
\hline 10 & 1.0 & 7.1 & TGA operated & no & - & 10 & 0.5 & 6.5 & AVSD+PH & yes & $\mathrm{D}$ \\
\hline 11 & 1.2 & 8.2 & TOF $+\mathrm{ASD}$ & yes & - & [1] & 1.3 & 10.4 & PS & no & $\mathrm{D}$ \\
\hline 12 & 1.3 & 9.4 & PS & yes & - & 12 & 1.4 & 9.8 & $V S D+P H$ & no & - \\
\hline 13 & 1.7 & 11.6 & PS & no & $\mathrm{D}$ & 13 & 1.4 & 10.7 & TOF & yes & D \\
\hline 14 & 1.8 & 15.3 & TOF+DORV & yes & $\mathrm{D}$ & 14 & 1.5 & 8.5 & TOF & no & DF \\
\hline 15 & 1.9 & 9.8 & PAPVD & no & $\mathrm{DF}$ & 15 & 1.9 & 9.6 & ALCAPA & no & DF \\
\hline
\end{tabular}

Abbreviations: AVSD = atrioventricular septal defect, PDA = patent ductus arteriosus, TGA = transposition of great arteries, ASD = atrial septal defect, VSD = ventricular septal defect, PS = pulmonary stenosis, PH = pulmonary hypertony, $\mathrm{PA}=$ pulmonary atresia, TOF $=$ tetralogy of Fallot, DORV = double outlet right ventricle, PAPVD = partial anomalous pulmonary venous drainage, $\mathrm{CoA}=$ coarctation of aorta, $\mathrm{CM}=$ cardiomyopathy, ALCAPA = anomalous left coronary artery from pulmonary artery. Medication: $D=$ gititalis, $F=$ furosemide.

or fentanyl $0.5-1 \mu \mathrm{g} \cdot \mathrm{kg}^{-1}$ every two to three minutes to reach a level of sedation that allowed preparation of the skin and positioning of the patient without reaction. Regional anaesthesia (one per cent lidocaine) was used to infiltrate the groins.

To maintain a satisfactory level of sedation, alfentanil 3-5 $\mu \mathrm{g} \cdot \mathrm{kg}^{-1}$ or fentanyl $0.5 \mu \mathrm{g} \cdot \mathrm{kg}^{-1}$ were given in increments if the patient reacted to pain or discomfort (movement in extremities, vocalization, irregular changes in breathing pattern or beart rate). The anaesthetist continuously evaluated the patient's reactiveness and the level of sedation by the scale given in Table $\amalg$. Further-

TABLE II Scales used to evaluate patient's reactiveness and the level of sedation

Reactiveness scale

$5=$ no reactions

$4=$ mild reactions which did not disturb the cardiologist

$3=$ reactions which disturbed the cardiologist (mild leg or hip movements

$2=$ moderate leg or hip movements which produced temporary interruption of the cardiologist to continue the catheterisation

$I$ = marked movement of the body which interrupted the investigation for at least 30 seconds

Sedation scale

$5=$ not arousable

$4=$ arousable if shaken with power

$3=$ wakes up if shaken mildly or spoken to with loud voice

2 = open eyes spontaneously or when asked for

1 = patient is awake but mildly sedated more, the cardiologist who was unaware of the drugs given gave an independent opinion of the patient's reactiveness at the times of insertion of cardiac catheters, pressure measurements and angiography. The level of sedation was regarded satisfactory if both reactiveness and sedation scores were $\geq 4$.

Patients breathed 30 per cent oxygen in air spontaneously via a transparent face mask. Ventilation was manually assisted with a Jackson-Rees T-piece system if the patient became apnoeic for $>15 \mathrm{sec}$ or developed stridor affecting gas exchange. Most patients had both arterial and venous cannulations, shunt and pressure recordings, and at least two different angiograms. Because the directions of our $x$-ray tubes are unalterable, the patient had to be positioned at a 30 degree tilted head-up position with the neck hyperextended for four-chamber imaging.

The ECG, heart rate, arterial oxygen saturation (Biox 3700, Ohmeda), end-tidal carbon dioxide (Normocap, Datex), and rectal temperature were continuously monitored. End-tidal $\mathrm{CO}_{2}$ was sampled via an adaptor located $5 \mathrm{~mm}$ inside the nostril by using a continuous flow of 200 $\mathrm{ml} \cdot \mathrm{min}^{-1}$. Noninvasive blood pressure (Dinamap, Criticon) was recorded every fifth minute. Samples for blood gas analysis were taken from the aortic arch or left ventricle at least once during steady level of sedation. End-tidal $\mathrm{CO}_{2}$ was documented simultaneously. After catheterization, patients were taken to the recovery room where they remained until the pressure bandage could be 
removed and the patient was fully cooperative. Thereafter, feeding was allowed without restriction.

The individual induction doses and maintenance requirements of alfentanil or fentanyl were calculated. The maintenance requirement was the cumulative total dose given after induction divided by the duration of the sedation. The dose-requirements were compared among different age groups $(<0.5 \mathrm{yr}, 0.5-1.0 \mathrm{yr}$ and $>1 \mathrm{yr}$ of age) and between cyanotic and acyanotic patients by using ANOVA and t test with Bonferroni correction. Doseeffect curves were drawn by using log-probit transformation: ${ }^{5}$ individual dose-requirements were put in order of size on a logarithmic scale and the cumulative percentage of patients expressing a satisfactory sedation on a probit axis. The variations of individual blood pressures and heart rates during the study period were evaluated for every patient by dividing SD of individual pressure and heart rate readings taken at five-minute intervals by their mean values. Mean values $\pm \mathrm{SD}$ are shown. $P<0.05$ was considered statistically significant.

\section{Results}

The mean duration of catheterization was 2.8 (range 1.3-4.8) and 2.5 (range 1.3-4.0) hr in the alfentanil and fentanyl groups, respectively. A satisfactory level of sedation could be maintained in every patient in both groups. Average blood pressures and heart rates were comparable in the alfentanil and fentanyl groups. Mean values for patients $<0.5 \mathrm{yr}, 0.5-1.0 \mathrm{yr}$, and $>1.0 \mathrm{yr}$ were $87 / 49,91 / 42,95 / 41 \mathrm{mmHg}$, and $132,128,112$ beats. $\min ^{-1}$, respectively. Average individual variations of these values were six per cent for systolic and 11 per cent for diastolic arterial pressure, and six per cent for heart rate in both the alfentanil and fentanyl groups. They were not influenced by age.

Cardiologists recognized mild reactions (grade four) when largest cardiac catheters were inserted. They furthermore regarded every patient to be without any reactions at the times of pressure measurements and angiographies. The anaesthetist evaluated the level of sedation equal to or greater than grade four at all times following the induction in every patient.

Mean arterial carbon dioxide tensions were $43 \pm 5$ and $46 \pm 6 \mathrm{mmHg}$ in the alfentanil and fentanyl groups, respectively. They were not found to differ in different age groups or among the cyanotic and acyanotic patients. However, the patients having furosemide therapy had greater arterial $\mathrm{PCO}_{2}$ than other patients (49 vs $43 \mathrm{mmHg}$, $P<0.05$ ). Arterial $\mathrm{pH}$ was nomal in every patient. Its mean value was $7.36 \pm 0.02$. End-tidal $\mathrm{PCO}_{2}$ did not depend on the age but was less in cyanotic than in acyanotic patients, $38 \pm 4$ vs $44 \pm 6 \mathrm{mmHg}(P<0.01)$. Concurrently, end-tidal $\mathrm{CO}_{2}$ was 98 per cent of arterial

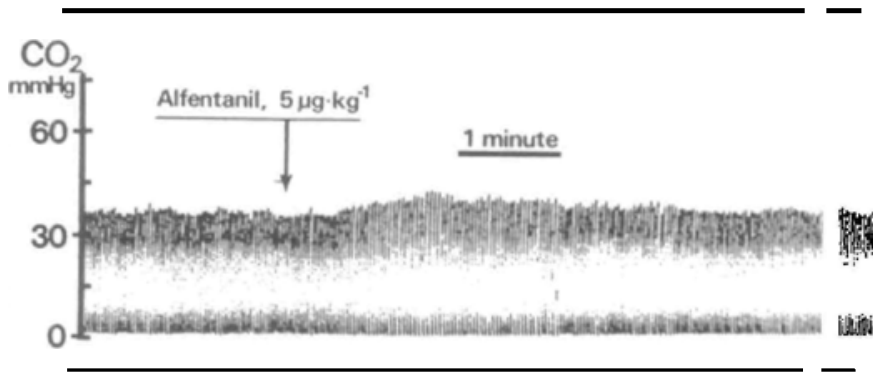

FIGURE 1 Carbon dioxide tracing at the time of alfentanil administration in a 0.6-yr-old boy with pulmonary atresia. Note the rapidly appearing reduction of ventilatory rate (from 32 to 26 breaths $\cdot \mathrm{min}^{-1}$ ) and elevation of $\mathrm{PCO}_{2}$ (from 36 to $41 \mathrm{mmHg}$ ) following $5 \mu \mathrm{g} \cdot \mathrm{kg}^{-1}$ alfentanil. These changes returned to pre-alfentanil levels within five minutes.

$\mathrm{CO}_{2}$-tension in acyanotic, but only 87 per cent in cyanotic patients $(P<0.01)$. The arterial to end-tidal $\mathrm{PCO}_{2}$ difference was $1 \pm 4 \mathrm{mmHg}$ in acyanotic and $6 \pm 3 \mathrm{mmHg}$ in cyanotic patients $(P<0.01)$.

Ventilation was assisted for less than a minute on four occasions due to a breath-holding in the alfentanil group: in one patient both during the induction of sedation and during positioning to four-chamber imaging, in another during induction and in one other during the prescribed positioning. Arterial oxygen saturation decreased by 20 per cent for less than a minute during one of these latter occasions. No other decreases from the individual baseline value of greater than five per cent in arterial oxygen saturation were detected. One patient in the fentanyl group required short ventilatory assistance due to breathholding during the four-chamber positioning. Figure 1 shows the rapid decrease in respiratory rate and increase in end-tidal $\mathrm{PCO}_{2}$ following an alfentanil increment.

The average induction dose of alfentanil was $20 \pm 6$ $\mu \mathrm{g} \cdot \mathrm{kg}^{-1}$. Thereafter, alfentanil increments were required every 6 th-9th min and the mean maintenance requirement was $30 \pm 12 \mu \mathrm{g} \cdot \mathrm{kg}^{-1} \cdot \mathrm{hr}^{-1}$. Patient's age did not have influence on these requirements. A highly significant correlation existed between individual induction dose and maintenance requirement (maintenance requirement $\left(\mu \mathrm{g} \cdot \mathrm{kg}^{-1} \cdot \mathrm{hr}^{-1}\right)=1.65 \times$ induction dose $(\mu \mathrm{g} \cdot$ $\left.\left.\mathrm{kg}^{-1}\right)-2.7\right)(\mathrm{r}=0.769)$.

The average induction dose of fentanyl was $2.5 \pm 1.1$ $\mu \mathrm{g} \cdot \mathrm{kg}^{-1}$. Further fentanyl increments were required at 15-25 min intervals. The average maintenance requirement was $1.5 \pm 0.6 \mathrm{\mu g} \cdot \mathrm{kg}^{-1} \cdot \mathrm{hr}^{-1}$. The potency ratio between alfentanil and fentanyl was 1:8 during the induction and the ratio between the dose-requirement for maintenance of sedation 1:20 (Figure 2).

Patients in both alfentanil and fentanyl groups stayed in the recovery room for an average of $1.8 \pm 0.4 \mathrm{hr}$. There was no nausea or vomiting during or after the study. Every patient expressed spontaneous micturition and had normal 


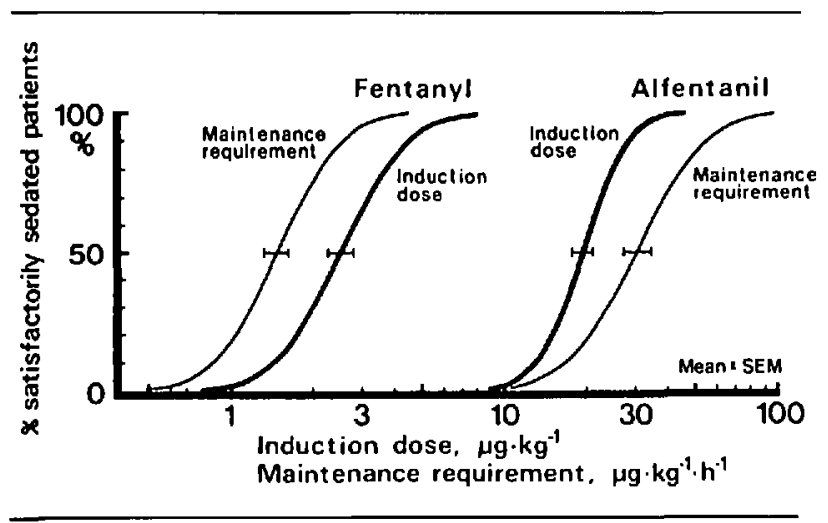

FIGURE 2 Dose-effect curves of fentanyl and alfentanil to induce and maintain an IV sedation for cardiac catheterization following flunitrazepam premedication. Satisfactory sedation was reached when the patient did not express any reaction attributable to pain or discomfort. The dose-effect curves are parallel and indicate a dose-requirement ratio between alfentanil and fentanyl of $1: 8$ during the induction and $1: 20$ during the maintenance of sedation.

oral feeding within the hour after return to a paediatric ward.

\section{Discussion}

The aim of the present study was twofold: first, to determine if alfentanil and fentanyl following oral flunitrazepam premedication could induce and maintain IV sedation for paediatric cardiac catheterization. Second, to determine the dose-requirements of alfentanil and fentanyl for IV sedation.

Oral flunitrazepam premedication produced a tranquil and calm state in every individual. Both alfentanil and fentanyl induced and maintained a level of sedation which abolished all reaction to pain and discomfort. The average dose of alfentanil required to allow skin washing and positioning without patient reaction was $20 \mu \mathrm{g} \cdot \mathrm{kg}^{-1}$. This dose is at the lower range of the usual induction dose of alfentanil during general anaesthesia. ${ }^{6,7}$ The average induction dose of fentanyl for sedation was $2.5 \mu \mathrm{g} \cdot \mathrm{kg}^{-1}$ indicating a potency ratio of $1: 8$ to alfentanil. A comparable dose ratio has been found in adults during general anaesthesia. $^{8}$

When the maintenance doses of alfentanil and fentanyl were titrated by small increments without producing respiratory depression, the average alfentanil and fentanyl requirements were 30 and $1.5 \mu \mathrm{g} \cdot \mathrm{kg}^{-1} \cdot \mathrm{hr}^{-1}$, respectively. This indicates a dose-requirement ratio of $1: 20$ which is comparable with that found in adults during maintenance of anaesthesia. ${ }^{9,10}$ The alfentanil or fentanyl requirements did not depend on the age or on the cyanotic state of the patient. This pharmacodynamic result supports the few existing pharmacokinetic studies in infants and children. ${ }^{11-14}$
The incremental administration of alfentanil and fentanyl was used instead of steady state infusion because guidelines for dosing these drugs for sedation in infants and small children are lacking. The respiratory effects of alfentanil appear almost immediately following the IV dose (see Figure 1). Thus, even small boluses of alfentanil ( $5 \mu \mathrm{g} \cdot \mathrm{kg}^{-1}$ ) may produce short periods of breath-holding or upper airway obstruction. This occurred in three patients and altogether four times after 428 such boluses in this study. Two of these occasions were during the induction of sedation. A probable reason was too frequent administration of small bolus doses of alfentanil so that the maximum cumulative effect was not waited for before next increment was given. The other two occasions of breath-holding occurred during the positioning to fourchamber imaging. It is likely that on some occasions airway manipulation is needed for this procedure (see Methods) even without any anaesthetic agent. Therefore, we regard the incidence of airway or ventilatory problems produced by alfentanil as very low in the present study. The incidence of breath-holding in the fentanyl group was even less, probably due to its slower onset time (time from injection to maximal effect) following IV administration. ${ }^{9}$

In this study, end-tidal carbon dioxide proved reliable in infants and small children during spontaneous breathing. Therefore, we recommend its use during IV sedation in children not only to have a device to reflect arterial $\mathrm{PCO}_{2}$ but also to detect any change in spontaneous breathing pattern of the child. Importantly enough, in acyanotic patients end-tidal $\mathrm{PCO}_{2}$ was 98 per cent of the arterial carbon dioxide tension, whereas in cyanotic patients the figure was only 87 per cent. These values are almost the same as found previously during open-heart surgery and explained by the different efficacy of ventilation and gas exchange in cyanotic and acyanotic patients. ${ }^{15}$ Thus, it is important to realize in clinical practice that if end-tidal $\mathrm{PCO}_{2}$ is maintained at the same level in cyanotic and acyanotic children, it indicates greater arterial $\mathrm{PCO}_{2}$ levels in cyanotic patients.

We found arterial carbon dioxide tensions to be significantly greater in patients receiving furosemide therapy than in other patients ( $49 \mathrm{vs} 43 \mathrm{mmHg}$ ). There are two possible explanations for this. First, furosemide is known to induce slight metabolic alkalosis ${ }^{16}$ which can be compensated for by slight hypercarbia to maintain normal arterial $\mathrm{pH}$. Second, patients having furosemide therapy have more severe myocardial failure and worse lung function than other patients. These more critically ill patients may have chronically elevated arterial $\mathrm{PCO}_{2}$ which is metabolically compensated. Whatever the explanation for the different $\mathrm{CO}_{2}$ tensions, it is clinically important to recognize this difference also during general anaesthesia when $\mathrm{CO}_{2}$ monitoring is used. 
In conclusion, both alfentanil and fentanyl were used safely following flunitrazepam premedication to sedate infants and small children for cardiac catheterization. Meticulous patient monitoring allowed the anaesthetist to titrate the level of sedation so that no reactions to pain or discomfort were present at the time the patient maintained spontaneous breathing. However, when incremental dosages were used, more peak and trough effects were seen especially in the alfentanil group than would be likely if the drugs were administered by continuous infusion. Fentanyl maintained more stable sedation and produced fewer side-effects than alfentanil, and is regarded as superior for IV sedation of long duration.

\section{References}

I Hickey $P R$, Wessel $D L$. Anesthesia in the pediatric cardiac catheterization laboratory. In: Kaplan JA (Ed.). Cardiac Anesthesia, 2nd ed., Orlando: Grune \& Stratton Inc., 1987; 2: 664 .

2 Ruckman RN, Keane JF, Freed MD, Ellison RC, Waldman $J D$. Sedation for cardiac catheterization. A controlled study. Pediatr Cardiol 1980; 1: 263-8.

3 Malviya S, Burrows SA, Johnsion AE, Benson LE. Anaesthetic experience with paediatric interventional cardiology. Can J Anaesth 1989; 36: 320-4.

4 Freed $M D$. Cardiac catheterization. In: Adams FH, Emmanouilides GC, Riemenschneider TA (Eds.). Moss' Heart Disease in Infants, Children, and Adolescents, 4th ed., Baltimore: Williams \& Wilkins, 1989; 130-47.

5 Litchfield JT, Wilcoxon F. A simplified method of evaluating dose-effect experiments. J Pharmacol Exp Ther 1949; 53: 99-113.

6 Ausems ME, Hug C Jr, Stanski DR, Burm AGL. Plasma concentrations of alfentanil required to supplement nitrous oxide anesthesia for general surgery. Anesthesiology 1986; 65: 362-73.

7 Bailey PL. Stanski TH. Pharmacology of intravenous narcotic anesthetics. In: Miller RD (Ed.). Anesthesia, 2nd ed., New York: Churchill Livingstone, 1986; 1: 757.

8 Stanski DR, Hug CC Jr. Alfentanil - a kinetically predictable narcotic analgesic. Anesthesiology 1982; 57: 435-8.

9 O'Connor M, Escarpa A, Prys-Roberts C. Ventilatory depression during and after infusion of alfentanil in man. Br J Anaesth 1983; 55 (suppl 2): 217-22.

10 Scot JC, Ponganis $K V$. Stanski $D R$. EEG quantitation of narcotic effect: the comparative pharmacodynamics of fentanyl and alfentanil. Anesthesiology 1985; 62: 234-41.

11 Roure P. Jean N, Leclerc AC, Cabanel N, Levron JC, Duvaldestin $P$. Pharmacokinetics of alfentanil in children undergoing surgery. Br J Anaesth 1987; 59: 1437-40.
12 Goresky GV, Koren G, Sabourin MA, Sale JP, Strunin $L$. The pharmacokinetics of alfentanil in children. Anesthesiology 1987; 67: 654-9.

13 d'Hollander JM, Hennis PJ, Burm AGL, Bovill JG. Alfentanil in infants and children with congenital heart defects. J Cardiothor Anesth 1988; 2: 12-7.

14 Koren G, Goresky G, Crean P, Klein J, MacLeod SM Pediatric fentanyl dosing based on pharmacokinetics during cardiac surgery. Anesth Analg 1984; 63: 577-82.

15 Yates AP, Lindahl SGE, Hatch DJ. Pulmonary ventilation and gas exchange before and after correction of congenital cardiac malformations. Br J Anaesth 1987; 59 : 170-8.

16 Weiner $I M$, Mudge $G H$. Diuretics and other agents employed in the mobilization of edema fluid. $I n$ : Gilman AG, Goodman LS, Rall TW, Murad F (Eds.). The Pharmacological Basis of Therapeutics, 7th ed., New York: MacMillan Publishing Co., 1985: 897. 